\title{
Endogenous job destructions and the distribution of wages is $^{2}$
}

\author{
Arnaud Chéron ${ }^{\mathrm{a}, \mathrm{b}, *}$, Bénédicte Rouland ${ }^{\mathrm{b}}$ \\ ${ }^{a}$ EDHEC Business School, France \\ b University of Le Mans (GAINS-TEPP), Faculté de droit et de Sciences Économiques, Avenue Olivier Messiaen, 72085 Le Mans Cedex 9, France
}

\section{A R T I C L E I N F O}

\section{Article history:}

Received 31 August 2010

Received in revised form 16 June 2011

Accepted 11 July 2011

Available online 22 July 2011

\section{Keywords:}

Wage distribution

Matching

Firing

Heterogeneity

\begin{abstract}
A B S T R A C T
This paper considers a matching model with both idiosyncratic productivity shocks that hit jobs at random and heterogeneity of workers according to ex ante unobservable abilities. We argue that firms' decisions about reservation productivity can help explain the shape of wage distributions. This is shown from numerical experiments, calibrated to French data, by considering alternative ranges of productivity shocks.
\end{abstract}

(c) 2011 Elsevier B.V. All rights reserved.

\section{Introduction}

The theory of equilibrium unemployment with matching and endogenous job destructions (Mortensen and Pissarides (1994)) has become an extensively-used framework both to address empirical facts of the labor market dynamics and to provide important insights into the design of labor market policies. Despite recent debates about the empirical relevance of the Nash-bargaining of wages (see Shimer (2005a) and Hall, (2005a)), this framework undoubtedly helps explain stylized facts characterizing labor market flows (Cole and Rogerson (1999)), unemployment dynamics (Pissarides (2009)) and real business cycle features (Andolfatto (1996), Merz (1995) or Chéron and Langot (2004)). This framework is also well suited to show how employment protection, hiring subsidies or labor taxes can be used to improve welfare (see among many others Millard (1996), Mortensen and Pissarides (1999), Pissarides (2000) or more recently Chéron et al. (2011)).

Since the end of the 1990s, another strand of the search-matching literature has focused on wage dispersion, considering on-the-job search rather than endogenous firing decisions. Burdett and Mortensen (1998) stressed the role of search frictions within an on-the-job search background in generating wage dispersion despite

\footnotetext{
is We are grateful to David Jaeger (the Editor) and two anonymous referees for thoughtful comments and suggestions. We have also received helpful comments on earlier drafts of this article from participants at the APET 2009 meeting, EEA 2009 meeting, Journées LAGV 2010 and EALE 2010 meeting, with a particular mention to Bruno Decreuse. The usual disclaimer applies.

* Corresponding author at: EDHEC Business School, France.

E-mail addresses: acheron@univ-lemans.fr (A. Chéron), benedicte.rouland.etu@univ-lemans.fr (B. Rouland).
}

having homogenous workers and firms. Subsequent work by Bontemps et al. (1999), Bontemps et al. (2000), Postel-Vinay and Robin (2002) and Cahuc et al. (2006) mainly emphasized the effect of market frictions in combination with heterogeneous productivities of both jobs and workers' abilities as a way to fit the distribution of wages. Wage dispersion is usually assumed to arise from on-the-jobsearch and existing models are usually characterized by exogenous firings. In contrast, this paper aims at showing that firms' firing decisions in the context of idiosyncratic productivity shocks can help explain the shape of the wage distribution.

Our paper also makes an empirical contribution. While it is widely known that OECD countries are characterized by hump-shaped wage distributions (see Fig. 3b in Jolivet et al. (2006)), little attention has been paid to the shape of employment to unemployment transition rates according to workers' position in the wage distribution, and therefore to the potential implication of those transitions in explaining wage dispersion. To give further insights into this issue, we consider the French experience, which shows recurrent stylized facts at the aggregate level as well as inside skill groups: a lognormal-like shape of wage distributions and a negative relationship between employment to unemployment transition rates and wage deciles (see Section 3).

Drawing a parallel between these empirical observations serves as guideline for the construction of a simple labor market model which has to deliver such quantitative outcomes. In particular, we consider a job creation-job destruction model in line with Mortensen and Pissarides (1994) extended to account for heterogeneous workers with ex ante unobservable abilities. There are two kinds of heterogeneity into the model: (i) each firm-job pair is hit by idiosyncratic productivity shocks, and (ii) each worker differs according to her ability. As the latter is assumed to be ex ante unobservable by firms, we consider non-directed 
search. ${ }^{1}$ The lower bound of a productivity shock below which a job is closed down is determined by a reservation productivity of firms that obviously depends on worker's ability, only observed ex post. This endogenous reservation productivity is the key decision in the model since it determines how the combination of the exogenous distributions of shocks and abilities leads to generate the endogenous distribution of wages. We use numerical experiments to emphasize the explanatory power of firms' reservation productivity decision rule. We then argue that the model can mimic the decreasing relationship between employment to unemployment transition rates and wage deciles, and this helps explain the shape of wage distributions, as long as we allow for a sufficiently high range of productivity shocks. This result occurs despite considering a conventional Pareto distribution of abilities that would unambiguously imply strictly decreasing wage densities in case of exogenous separation rates.

The remaining of the paper is organized as follows. The next section presents the framework. The third one gives a description of the data set and computed statistics. The fourth section deals with computation experiments. The last section concludes.

\section{Model}

\subsection{Assumptions and labor market flows}

We consider a continuous-time matching model in steady state with endogenous job creations and destructions. Workers are heterogeneous due to unobservable ability $a$ along the interval $\left[\underline{a}_{\bar{a}}\right]$, with $F(a)$ the exogenous cumulative distribution function of abilities. When a firm opens a job vacancy, it knows the distribution function of abilities but does not ex ante observe the ability of the contacted worker. This ability is revealed once the worker has been hired.

Each firm has one job. The productivity of the job/firm depends not only on the worker's ability, but also on a job specific random component. The idiosyncratic productivity shock, denoted $\varepsilon$, is realized at the time of job creation and occurs according a Poisson rate $\lambda$ where $G(\varepsilon)$ is the $c d f, \forall \varepsilon \in[\varepsilon, 1] .{ }^{2}$ The overall productivity of the job is therefore given by $\varepsilon+a$. Further, the productivity threshold $R(a)$ determines the lowest productivity value a firm will accept to maintain a job. This value obviously depends on workers' ability. Accordingly, the overall job destruction rate is given by $\lambda G(R(a))+s$, where $s$ is an exogenous rate of separation. ${ }^{3}$

Following Dolado et al. (2009) or Chéron et al. (2011) among others, we consider heterogeneous workers in the context of a non-directed search process. ${ }^{4}$ More precisely, we assume that firms cannot ex ante direct their search toward (unobservable) workers' ability. An aggregate matching function $M(v, u)$ then determines the number of hirings, where $v$ and $u$ denote the number of vacancies and unemployed workers, respectively. The matching function is increasing and concave in both arguments. Accordingly, the contact rate for each worker is given by $\theta q(\theta) \equiv \frac{M(v, u)}{u}$, where $q(\theta) \equiv \frac{M(v, u)}{v}$, and $\theta \equiv \frac{v}{u}$ is the labor market tightness.

\footnotetext{
1 The introduction of workers heterogeneity in a matching model with non-directed search clearly raises (in)efficiency issues: the Hosios condition no longer achieves efficiency. Such theoretical issues have been examined by Shimer and Smith (2001), Albrecht and Vroman (2002), Blàquez and Jansen (2008) or Chéron et al. (2011) for instance. Yet, as our model does not add any new interesting insights about that point, and because our focus is above all related to the shape of wage distributions, efficiency issues are not addressed in this paper.

${ }^{2}$ Alternative values of $\varepsilon$ will be considered in numerical experiments in Section 4 to highlight the role of endogenous reservation productivity in explaining the shape of the wage distribution.

${ }^{3}$ Introducing $s$ and letting it vary from zero to positive values will allow us in Section 4 to assess the quantitative importance of endogenous job destructions. This indeed allows for a positive unemployment rate when $\varepsilon=1$.

${ }^{4}$ Chéron et al. (2011) consider age-differentiated workers but age discrimination is not allowed, while there are two types of workers differentiated by their level of education in the economy of Dolado et al., 2009.
}

The transition rate from unemployment to employment for a worker with ability $a$ is therefore given by $\theta q(\theta)[1-G(R(a))]$.

Lastly, denoting $u(a)$ the number of unemployed workers with ability $a$ and defining $f(a) \equiv F^{\prime}(a)$, equilibrium labor market flows in steady state imply:

$u(a) \theta q(\theta)=[s+\lambda G(R(a))][f(a)-u(a)] \forall a \in[\underline{a}, \bar{a}]$

The overall unemployment rate is written: $u=\int_{a}^{\bar{a}} u(a) d a$.

\subsection{Firing and hiring behaviors}

The value of a filled job is assumed to be defined by:

$r J(a, \varepsilon)=a+\varepsilon-w(a, \varepsilon)+\lambda \int_{R(a)}^{1} J(a, x) d G(x)-(s+\lambda) J(a, \varepsilon)$

with $r$ the interest rate and where $w(a, \varepsilon)$ stands for the wage.

It is not in the best interest of firms to keep workers on working if the job value is negative, i.e. $J(a, \varepsilon) \leq 0 .{ }^{5}$ Therefore, the threshold value for productivity $R(a)$ satisfies $J(a, R(a))=0$ and is positively related to wages but negatively to the labor hoarding value of the job since a new productivity is drawn at rate $\lambda$ from the set $[\underline{\varepsilon}, 1]$ :

$R(a)=-a+w(a, R(a))-\lambda \int_{R(a)}^{1} J(a, x) d G(x)$

The recruiting policy is determined by the expected average value of the job once filled. But as firms cannot ex ante target hirings among heterogeneous workers and as a particular productivity shock is drawn once a worker is contacted, the vacancy decision depends both on abilities' and on productivity shocks' distributions. The value of a vacancy is therefore defined as follows:

$r V=-c+q(\theta) \int_{\underline{a}}^{\bar{a}}\left(\frac{u(a)}{u}\right)\left\{\int_{R(a)}^{1}[J(a, \varepsilon)-V] d G(\varepsilon)\right\} d a$

with $c \geq 0$ the flow cost of recruiting a worker.

A standard free entry condition (such that the value of vacancies vanishes in equilibrium) then determines the labor market tightness $\theta$ and implies that the expected recruitment cost equalizes ex ante the expected value of job creation:

$\frac{c}{q(\theta)}=\int_{\underline{a}}^{\bar{a}}\left(\frac{u(a)}{u}\right)\left\{\int_{R(a)}^{1} J(a, \varepsilon) d G(\varepsilon)\right\} d a$

\subsection{Wage setting}

We consider the conventional assumption of Nash-bargaining of wages. ${ }^{6}$ Firms and workers share the global surplus generated by a job according to their relative bargaining power: $S(a, \varepsilon)=J(a, \varepsilon)+$ $W(a, \varepsilon)-U(a)$, where workers' values of unemployment and employment are respectively given by:

$$
\begin{aligned}
r U(a)= & z+\theta q(\theta) \int_{R(a)}^{1}[W(a, x)-U(a)] d G(x) \\
r W(a, \varepsilon)= & w(a, \varepsilon)+\lambda \int_{R(a)}^{1}[W(a, x)-W(a, \varepsilon)] d G(x) \\
& +[s+\lambda G(R(a))][U(a)-W(a, \varepsilon)]
\end{aligned}
$$

\footnotetext{
${ }^{5}$ Actually, due to Nash bargaining of wages, this separation rule is also optimal from workers' point of view.

${ }^{6}$ Since Shimer (2005a) and Hall and Milgrom (2008), the Nash-bargaining of wages is somewhat a disputed assumption, at least from an empirical perspective. Hall and Milgrom (2008) point out that the rigidity of wages helps explain the observed volatility of unemployment over the business cycle. Nevertheless, Pissarides (2009) rehabilitates the Nash-bargaining showing that the failure of the MortensenPissarides' framework rather relies on the size of labor turnover costs which are typically understated.
} 
The standard Nash-sharing rule is:

$W(a, \varepsilon)-U(a)=\gamma S(a, \varepsilon)$

where $\gamma$ stands for the bargaining power of workers. The following expression for the wage can be then derived ${ }^{7}$ :

$w(a, \varepsilon)=(1-\gamma) z+\gamma(a+\varepsilon)+\gamma \theta q(\theta) \int_{R(a)}^{1} J(a, x) d G(x)$

In the context of ex ante unobservable heterogeneity and following Chéron et al. (2011), we show that the way search costs enter into the wage equation depends on the ex post value of the worker relative to the ex ante expected average value of job creation, defined over the whole pool of unemployed workers. ${ }^{8}$ More precisely, making use of

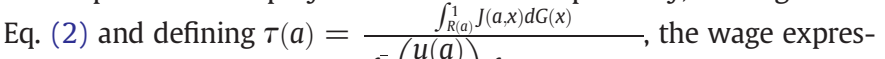
sion can be rewritten as: $\quad \int_{\underline{a}}^{\bar{a}}\left(\frac{u(a)}{u}\right) \int_{R(a)}^{1} J(a, x) d G(x) d a$

$w(a, \varepsilon)=\gamma[a+\varepsilon+c \theta \tau(a)]+(1-\gamma) z$

High-ability workers are characterized by $\tau(a)>1$, which implies that they are rewarded for more than the saving of the average search costs $(c \theta)$. Both productivity $a$ and search costs $c \theta \tau(a)$ then push up wages. Conversely, workers with low abilities earn low wages not only due to a lower productivity value (for a given $\varepsilon$ ) but also because due to a lower imputed value of search costs. Therefore, the density of low-wages should be high if the density of low-ability workers is high. On the other hand, a low density of high-ability workers should translate into low densities of high-wages.

Our model also implies, however, that heterogeneous workers may earn the same wage: a low-ability worker who would have been hit by a good shock may earn the same wage as a high ability one but who would have been hit by a bad shock. This introduces a new mechanism with regard to the wage distribution that is related to the endogenous productivity threshold $R(a)$, which tends to decrease the density of low wages but to increase the one of medium wages. Typically, the reservation productivity is high (low) for low(high)ability workers (see property 1 below). Accordingly, the set of wages, defined over $w(a, 1)-w(a, R(a))$, is narrower for low-ability workers while it could be very large for high-ability workers, as firms may have interest to keep them on working in case of very bad shock. ${ }^{9}$ All else being equal, both high productivity thresholds for low-ability workers and low productivity thresholds for high-ability workers should therefore contribute to increase the density of medium wages.

\subsection{Equilibrium definition}

The conditions that simultaneously determine the labor market tightness $\theta$, the set of productivity thresholds $R(a)$ and unemployment levels by ability $u(a), \forall a \in[\underline{a}, \bar{a}]$ can be now defined:

\footnotetext{
${ }^{7}$ Depending on productivity draws, wage earnings may increase or decrease at each period. In France, approximately $40 \%$ of workers experience a fall in their real wages from one year to another.

${ }^{8}$ In Chéron et al. (2011), the role search costs play into the wage equation is emphasized considering age-differentiated workers.

9 Considering heterogeneous workers in terms of education instead of ability, Dolado et al. (2009) argue that the set of wages could also be very large for higheducated workers. Their mechanism rests on on-the-job search in a context of heterogeneous firms (creating simple and complex jobs) and exogenous job destruction. While high-skill workers optimally accept simple rather than complex job, firms accept these matches at a lower wage than with appropriately matched workers (low-skill workers in simple jobs) as they anticipate that over-educated candidates may quit as soon as a better job becomes available. This gives rise to strong wage inequalities among those workers, depending on the job they work in. In our model, wage inequalities are also strong among high-abilities workers as they depend on idiosyncratic productivity shocks that can be bad or good.
}

Proposition 1. The labor market equilibrium is defined by the following set of equations:

$$
\begin{aligned}
& \frac{c}{q(\theta)}=\left(\frac{1-\gamma}{r+s+\lambda}\right) \int_{\underline{a}}^{\bar{a}}\left(\frac{u(a)}{u}\right) \int_{R(a)}^{1}[1-G(\varepsilon)] d \varepsilon d a \\
& R(a)=-a+z-\left(\frac{\lambda-\gamma \theta q(\theta)}{r+s+\lambda}\right) \int_{R(a)}^{1}[1-G(\varepsilon)] d \varepsilon \\
& u(a)=f(a) \frac{s+\lambda G(R(a))}{\theta q(\theta)+s+\lambda G(R(a))} ; \quad u=\int_{\underline{a}}^{\bar{a}} u(a) d a
\end{aligned}
$$

Proof. First, from $J(a, R(a))=0$ and the wage expression (3) and using the fact that $(r+s+\lambda) J(a, \varepsilon)-(r+s+\lambda) J(a, R(a))=\varepsilon-R(a)-$ $w(a, \varepsilon)+w(a, R(a))$, it follows that $(r+s+\lambda) J(a, \varepsilon)=(1-\gamma)[\varepsilon-R$ (a)]. Second, integrating by parts leads to $\int_{R(a)}^{1}[\varepsilon-R(a)] d G(\varepsilon)=$ $\int_{R(a)}^{1}[1-G(\varepsilon)] d \varepsilon$.

Property 1. The labor market equilibrium is characterized by $R^{\prime}(a)<0$.

Proof. The proof is straightforward by noticing that $d R=$ $-d a+\left(\frac{\lambda-\gamma \theta q(\theta)}{r+{ }_{1} \lambda}\right)[1-G(R)] d R$, which implies that $\frac{d R}{d a} \equiv R^{\prime}(a)=$ $-\frac{1}{1-\left(\frac{\lambda-\gamma \theta q(\theta)}{r+\lambda}\right)[1-G(R)]}<0, \forall \lambda, \gamma$.

According to this property, the higher the worker's ability, the lower the productivity threshold below which the job is not maintained. This suggests, therefore, that high-ability workers may keep their jobs even though bad productivity shocks hit them.

\section{Data}

To examine the correlation between the employment to unemployment transition rates and wages, we used French Labor Force survey ("Enquête Emploi" provided by INSEE) in 1992, 1997, 2002 and 2007. For each year, we defined our sample in the following way. We focused on the population of respondents who were working at the beginning of the first quarter and considered their situation on the labor market at the end of the quarter. We chose to select the subsample of workers aged from 18 and 60, working full-time or parttime jobs and employed by the private sector. We exclude farmers and self-employed. We also deleted the few observations with missing values, mainly because of missing wages. Lastly, workers were sorted according to their socioeconomic status at the beginning of the quarter. In particular, we defined four groups of workers according their skill level: high-skilled workers (executives and managers), mediumskilled workers (technical supervisors and technicians), low-skilled workers (skilled manual workers) and unskilled workers (unskilled workers and employees).

We focused on the two following variables of interest. The first one was about transitions from employment to unemployment. Therefore, we defined a dummy variable which was equal to one when the worker has experienced a transition from employment to unemployment between the beginning and the end of the first quarter of each year under consideration. The second outcome was the monthly wage level, expressed in Euros. Wages were divided into ten intervals computed from nine wage deciles. For each skill level, workers were then sorted according to the wage interval they belong to at the beginning of the quarter. We computed then quarterly employment-unemployment transition rates both by skill level and wage interval.

Firstly, Fig. 1 below shows the log-normal-like shape of wage distributions within skill groups for 2007, which suggests that France can truly represent what is observed in most of OECD countries. Fig. 2 draws the same picture for 1992-2007. Ratios by skill of wage deciles to the median wage are also provided in Table $1 .^{10}$

\footnotetext{
${ }^{10}$ Quantitative properties of our model will be compared to those statistics.
} 

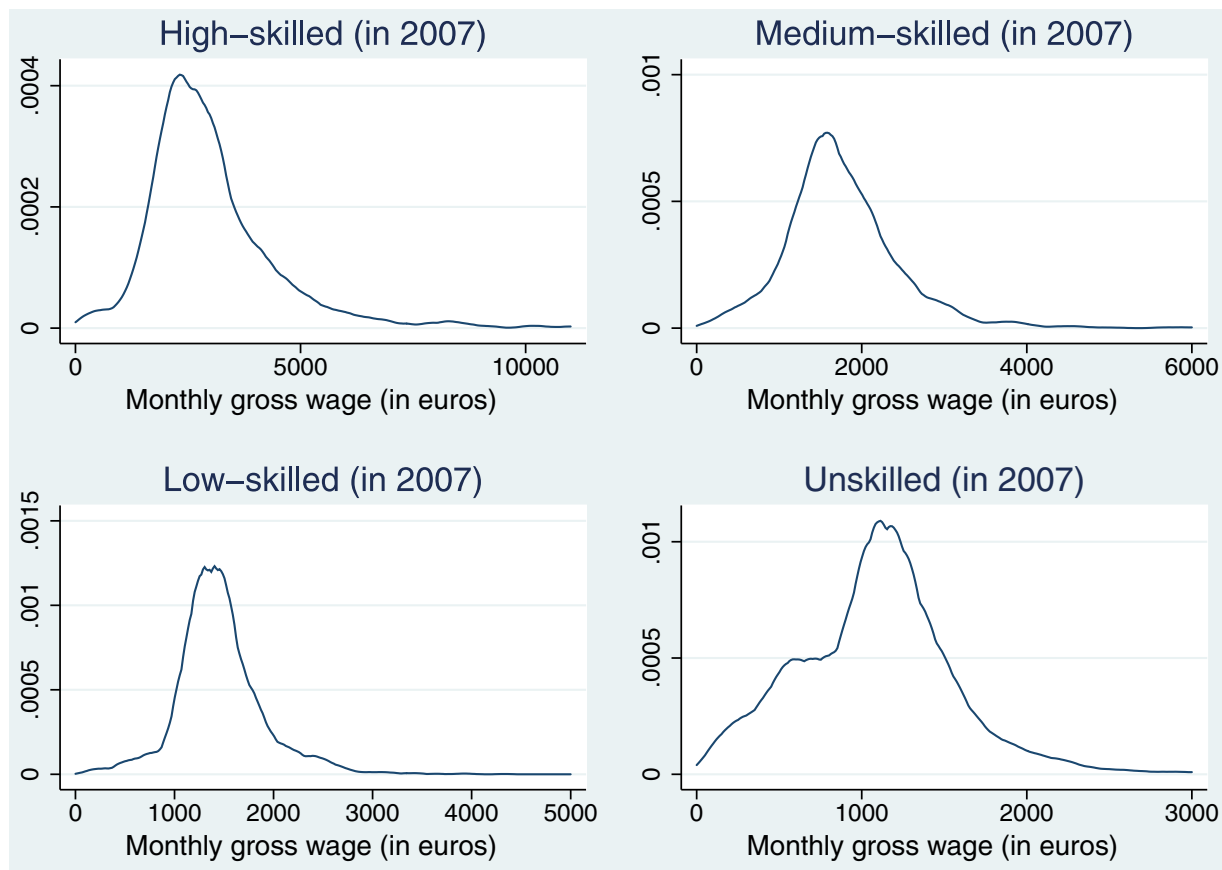

Fig. 1. Wage distributions in 2007 French LFS, by skill.

Secondly, Fig. 3 shows that France is also characterized by a negative correlation between wage deciles and transition rates from employment to unemployment within each wage interval, both at the aggregate level and by skills. Fig. 4 emphasizes also that such a decreasing relationship holds over the 1992-2007 period. We do not report statistics related to high-skilled workers as managers experience only very few employment to unemployment transitions in the French LFS (at least for high wage deciles). Furthermore, this negative slope is all the more important that wages below the fifth decile are considered.

The next section aims at enlightening the potential empirical relevance of combining productivity shocks with ex ante unobservable heterogeneity of workers as a way to explain the distribution of wages. Obviously, our approach leaves aside several dimensions of the labor market that have turned out to be important determinants of the wage distribution, such as on-the-job search (see e.g.Bontemps et al. (2000), Postel-Vinay and Robin (2002)). However, our objective is to focus on a particular context that has not been yet examined - heterogeneous unobservable abilities of workers interacting with idiosyncratic productivity shocks - and to show that firms' decision rule about productivity can help explain the shape of the wage distribution.

\section{Simulations of the equilibrium wage distribution}

Our overall strategy consists in showing how sensitive is the wage distribution to endogenous productivity thresholds, by letting the lower bound of productivity shocks $\underline{\varepsilon}$ vary. An important implication of our model is that the distribution of wages depends on endogenous productivity thresholds. Accordingly, the shape of wage dispersion can be dissimilar to the distribution we typically assume for workers' abilities. This is clearly so in case of exogenous job destruction (i.e. $\underline{\varepsilon}=1$ and $s>0$ ).

We briefly present the model calibration, discuss the computation of wage distributions and finally examine some numerical experiments.

\subsection{Calibration}

We consider a quarterly calibration of the model. The first set of parameters is based on external information. The second one aims at replicating some stylized facts that characterize the French low-skilled workers ("ouvriers qualifiés") data set over the 2006-2007 period. We consider a homogenous period of the business cycle (before the current economic crisis) as our model does not allow for macroeconomic shocks and fluctuations. ${ }^{11}$ As detailed below, we consider two targets: the unemployment rate and the employment to unemployment exit rate over this period. The empirical investigation of the quantitative properties of the model then consists in examining (i) the shape of the wage distribution, and (ii) statistics summarizing wage deciles and average separation rates within each wage decile interval. We consider three specifications of productivity shocks that allow us to analyze the sensitivity of the quantitative properties of the model.

As a preliminary step, specifications of functional forms for the matching function and the distributions of idiosyncratic shocks and abilities are required. We choose the simplest functions based on existing assumptions in the literature. In particular, as in Mortensen and Pissarides, 1994, we consider a uniform distribution of shocks $G(x)=x \forall x \in[\underline{\varepsilon}, 1]$ and a Cobb-Douglas matching function $M(v, u)=v^{\psi} u^{1-\psi}$. We also follow Mortensen (2003) by assuming that the dispersion of abilities is defined by a Pareto distribution. More specifically, we assume that $F(a)=2\left(1-\frac{1}{a}\right) \forall a \in[1,2] .{ }^{12}$

These specifications imply that the equilibrium conditions collapse to:

$$
\begin{aligned}
& c \theta^{1-\psi}=\left(\frac{1-\gamma}{r+s+\lambda}\right) \int_{1}^{2}\left(\frac{u(a)}{u}\right) \frac{1}{2(1-\underline{\varepsilon})}[1-R(a)]^{2} d a \\
& R(a)=-a+z-\left(\frac{\lambda-\gamma \theta^{\psi}}{r+s+\lambda}\right) \frac{1}{2(1-\underline{\varepsilon})}[1-R(a)]^{2} \\
& u(a)=\left(\frac{2}{a^{2}}\right)\left(\frac{s+\lambda G(R(a))}{\theta^{\psi}+s+\lambda G(R(a))}\right) ; u=\int_{1}^{2} u(a) d a
\end{aligned}
$$

\footnotetext{
11 Postel-Vinay and Robin (2002) and Jolivet et al. (2006) (among many others) follow a similar strategy to estimate their steady-state search model.

12 Alternative calibrations of $a$ and $a$ would lead to similar quantitative conclusions. As we are interested in the shape of wage distributions, wage levels do not matter. Hence, we will report simulation results by dividing wages by the lowest wage in the economy.
} 

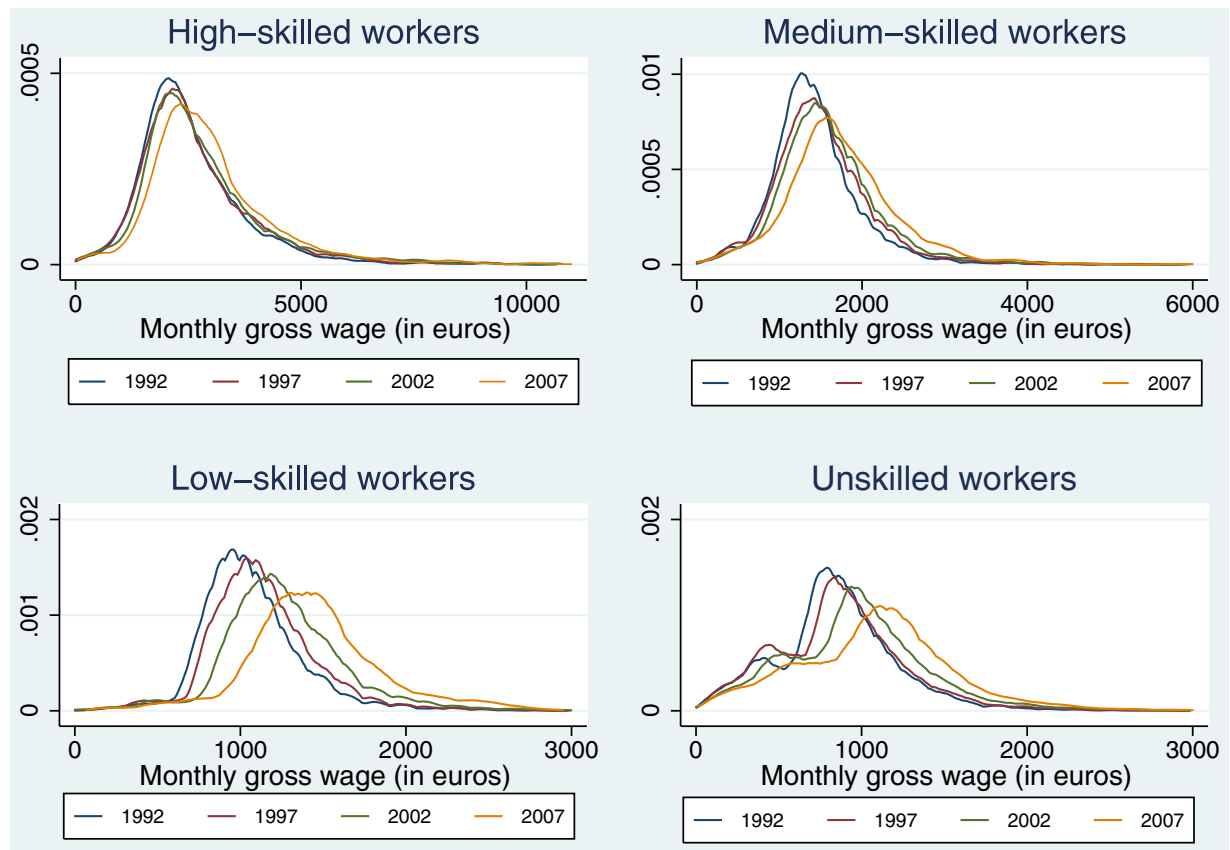

Fig. 2. Wage densities by skill in 1992, 1997, 2002 and 2007 (in France).

The first set of parameters is consistent with conventional values assumed in the literature: $r=0.01$ and $\psi=\gamma=0.5$. The second set of parameters then includes $\{z, c, s, \lambda, \underline{\varepsilon}\}$. The role of productivity shocks and endogenous productivity threshold crucially depends on the value of $\varepsilon$. Therefore, we examine three model specifications to underline mechanisms at work:

- "Model 1" is the benchmark model with endogenous job destruction but without any exogenous job destruction. Hence, we set $s=0$. Following Ljungqvist and Sargent (2008), the Poisson arrival rate of productivity shocks is consistent with an expected shock every two

Table 1

Ratios by skill of wage deciles to the median wage (in France)*.

\begin{tabular}{|c|c|c|c|c|c|c|c|c|c|c|}
\hline Workers & $\begin{array}{l}\text { D5/average } \\
\text { wage }\end{array}$ & $\begin{array}{l}\text { D1/ } \\
\text { D5 }\end{array}$ & $\begin{array}{l}\text { D2/ } \\
\text { D5 }\end{array}$ & $\begin{array}{l}\text { D3/ } \\
\text { D5 }\end{array}$ & $\begin{array}{l}\text { D4/ } \\
\text { D5 }\end{array}$ & $\begin{array}{l}\text { D5/ } \\
\text { D5 }\end{array}$ & $\begin{array}{l}\text { D6/ } \\
\text { D5 }\end{array}$ & $\begin{array}{l}\text { D7/ } \\
\text { D5 }\end{array}$ & $\begin{array}{l}\text { D8/ } \\
\text { D5 }\end{array}$ & $\begin{array}{l}\text { D9/ } \\
\text { D5 }\end{array}$ \\
\hline \multicolumn{11}{|c|}{ High-skilled } \\
\hline In 1992 & 0.89 & 0.6 & 0.73 & 0.83 & 0.92 & 1 & 1.11 & 1.25 & 1.43 & 1.78 \\
\hline In 1997 & 0.89 & 0.59 & 0.72 & 0.83 & 0.91 & 1 & 1.10 & 1.27 & 1.46 & 1.80 \\
\hline In 2002 & 0.87 & 0.62 & 0.73 & 0.82 & 0.92 & 1 & 1.12 & 1.25 & 1.47 & 1.85 \\
\hline In 2007 & 0.90 & 0.62 & 0.74 & 0.83 & 0.91 & 1 & 1.10 & 0.94 & 1.42 & 1.73 \\
\hline \multicolumn{11}{|c|}{ Medium-skilled } \\
\hline In 1992 & 0.94 & 0.64 & 0.78 & 0.85 & 0.93 & 1 & 1.08 & 1.17 & 1.30 & 1.53 \\
\hline In 1997 & 0.95 & 0.61 & 0.74 & 0.84 & 0.91 & 1 & 1.08 & 1.18 & 1.31 & 1.53 \\
\hline In 2002 & 0.92 & 0.63 & 0.76 & 0.85 & 0.93 & 1 & 1.08 & 1.20 & 1.31 & 1.57 \\
\hline In 2007 & 0.96 & 0.61 & 0.75 & 0.85 & 0.92 & 1 & 1.08 & 1.10 & 1.31 & 1.53 \\
\hline \multicolumn{11}{|c|}{ Low-skilled } \\
\hline In 1992 & 0.94 & 0.74 & 0.82 & 0.89 & 0.94 & 1 & 1.06 & 1.13 & 1.24 & 1.42 \\
\hline In 1997 & 0.96 & 0.72 & 0.83 & 0.89 & 0.95 & 1 & 1.06 & 1.13 & 1.24 & 1.39 \\
\hline In 2002 & 0.95 & 0.73 & 0.81 & 0.88 & 0.95 & 1 & 1.07 & 1.15 & 1.25 & 1.41 \\
\hline In 2007 & 0.96 & 0.73 & 0.84 & 0.89 & 0.94 & 1 & 1.07 & 1.13 & 1.25 & 1.40 \\
\hline \multicolumn{11}{|l|}{ Unskilled } \\
\hline In 1992 & 0.97 & 0.44 & 0.68 & 0.83 & 0.91 & 1 & 1.09 & 1.18 & 1.32 & 1.55 \\
\hline In 1997 & 0.97 & 0.44 & 0.61 & 0.80 & 0.93 & 1 & 1.09 & 1.20 & 1.35 & 1.59 \\
\hline In 2002 & 0.97 & 0.44 & 0.62 & 0.80 & 0.93 & 1 & 1.09 & 1.18 & 1.33 & 1.55 \\
\hline In 2007 & 1 & 0.43 & 0.61 & 0.79 & 0.91 & 1 & 1.09 & 1.18 & 1.30 & 1.49 \\
\hline
\end{tabular}

* The first column "D5/average wage" gives the ratio of the fifth wage decile to the average wage. years, i.e. $\lambda=1 / 8$. The support of productivity shocks is assumed to be continuously distributed over the range $[-1,1]$ by setting $\underline{\varepsilon}=-1$. Accordingly, the lowest productivity $(a+\varepsilon)$ is zero in this economy and the highest one is 3 as $a \in[1,2]$. We choose $z=0.52$ to get an average job destruction rate of $2.1 \%$ per quarter, consistent with the observed employment to unemployment exit rate for the skilled manual workers over the period 2006-2007 in France. The labor market tightness $\theta$ should be consistent with an unemployment rate of $8.2 \%$ (from Eq. (7)), which gives the value of $c$ as a solution of Eq. (5). ${ }^{13}$ This implies that the contact rate is $\theta^{\psi}=35 \%$, which means that it takes on average 8.5 months to get a job offer. The simulated average duration of an unemployment spell is then approximately 11 months.

To test the sensitivity of the distributional implications of the model, we then consider two other calibrations:

- "Model 2" refers to the case of exogenous job destruction where it is assumed that $\underline{\varepsilon}=1$. There are no productivity shocks in this economy. Instead of Eqs. (5)-(7), the equilibrium is characterized by ${ }^{14}$ :

$$
\begin{aligned}
c \theta^{1-\psi} & =\int_{1}^{2}\left(\frac{u(a)}{u}\right)\left(\frac{(1-\gamma)(a+1-z)-\gamma c \theta}{r+s}\right) d a \\
u(a) & =\left(\frac{2}{a^{2}}\right)\left(\frac{s}{\theta^{\psi}+s}\right) ; \quad u=\int_{1}^{2} u(a) d a
\end{aligned}
$$

As we aim at comparing Model 2 with Model 1, home production is still set to $z=0.52$, and we assume $s=2.1 \%$ to match the average separation rate of low-skilled workers. $\theta$ (hence $c$ ) is also set to match the unemployment rate (8.2\%), which is now consistent with an unemployment spell of about 13 months for each ability.

\footnotetext{
${ }^{13}$ Actually, only the steady-state value of $\theta^{\psi}$ matters in our simulation procedure since Eqs. (6)-(7) for the productivity threshold and the unemployment, as well as upcoming Eq. (8) for the wage, are expressed as functions of $\theta^{\psi} . c$ then satisfies Eq. (7) for a given $\theta$.

${ }^{14}$ With only exogenous job destruction, $c \theta^{1-\psi}=J(a, 1)$ at equilibrium, where $J(a, 1)=\frac{a+1-w(a)}{r+s}$ and $w(a)=\gamma(1+a+c \theta)+(1-\gamma) z$.
} 

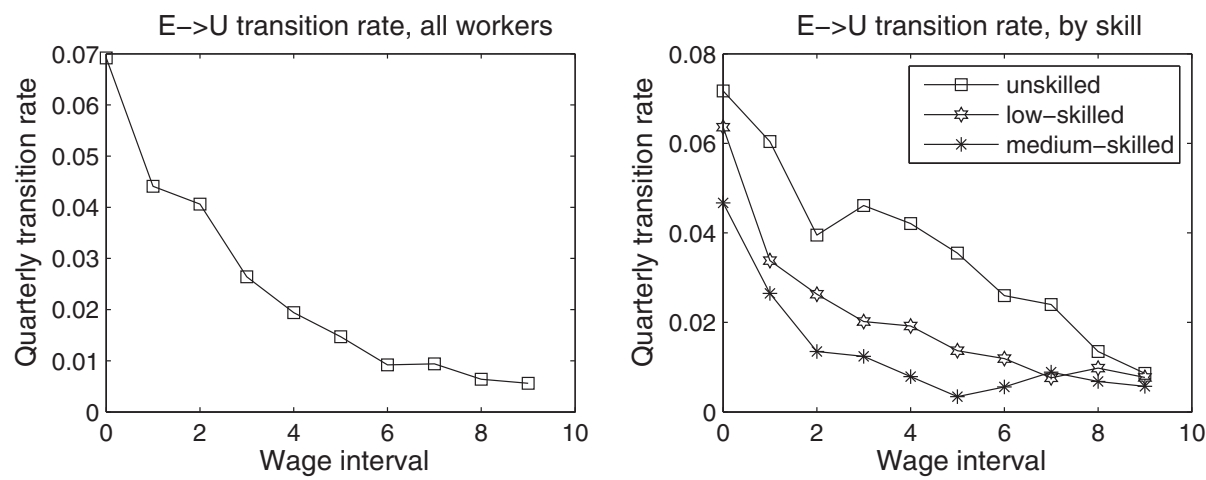

Fig. 3. Employment to unemployment transition $(\mathrm{E} \rightarrow \mathrm{U})$ rates in French LFS
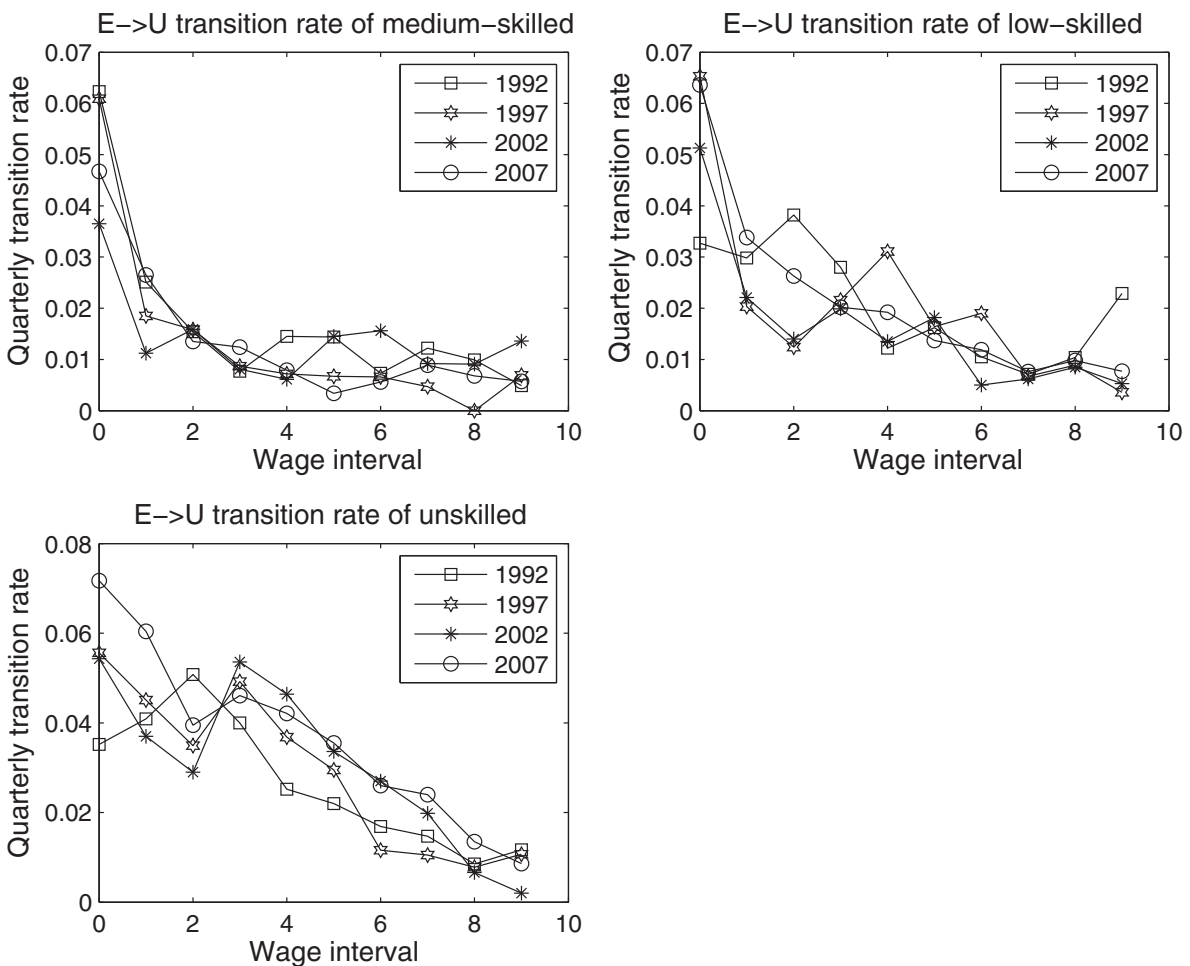

Fig. 4. Employment to unemployment (E->U) transition rates by skill in 1992, 1997, 2002 and 2007 (in France).

- "Model 3" is a mixed version of Model 1 and Model 2. It allows both for exogenous and endogenous productivity shocks but a smaller rate of exogenous job destruction is chosen: $s=1 \%$. Still, $\lambda=1 / 8$ (as in Model 1 ) and we assume $\underline{\varepsilon}=0$. Both remaining parameters, $z$ and $\theta$ (hence $c$ ), are set to fit the average exit rate from employment to unemployment and the unemployment rate. This leads to $z=1.29$, and the average duration of an unemployment spell is approximately 11 months.

\subsection{Computation of wage distribution}

Without any productivity shock (Model 2), the distribution of wages can be straightforwardly derived from that of abilities, as wages only depend on the ability $a$. More precisely, assuming (as in the calibration) $\varepsilon=1$, we get from Eq. (3) ${ }^{15}$ :

$$
\begin{aligned}
w(a) & =(1-\gamma) z+\gamma(a+1)+\gamma \theta q(\theta) J(a, 1) \\
& =\left(\frac{1-\gamma}{1+\gamma \Psi(\theta)}\right) z+\gamma\left(\frac{1+\Psi(\theta)}{1+\gamma \Psi(\theta)}\right)(a+1)
\end{aligned}
$$

\footnotetext{
${ }^{15}$ This equation is the same as $w(a)=\gamma(a+1+c \theta)+(1-\gamma) z$
}

with $\Psi(\theta)=\frac{\theta q(\theta)}{r+s}$ and making use of the fact that $J(a, 1)=$ $\frac{a+1-w(a)}{r+s}$. The corresponding density function of wages, denoted $\varphi(w)$, is then given by:

$$
\varphi(w)=\varphi(w(a))=f(a)-u(a)=f(a)\left(\frac{\theta^{\psi}}{s+\theta^{\psi}}\right) .
$$

From the Pareto distribution, $f(a) \equiv F^{\prime}(a)=\frac{2}{a^{2}}$, which leads to $f^{\prime}(a)<0$. Therefore, $\varphi^{\prime}(w)<0$ unambiguously. But such a strictly decreasing shape of the wage density function is clearly at odds with the well-documented hump-shaped wage distributions.

On the other hand, in the benchmark economy, the wage earning of a worker is not only related to her ability but also to idiosyncratic shocks that hit the job. Formally, this results in $w=w(a, \varepsilon)$ defined by Eq. (3), which can also be rewritten as:

$w(a, \varepsilon)=(1-\gamma) z+\gamma(a+\varepsilon)+\left(\frac{\gamma \theta^{\psi}}{r+\lambda+s}\right)\left(\frac{1-\gamma}{2(1-\underline{\varepsilon})}\right)[1-R(a)]^{2}$ 


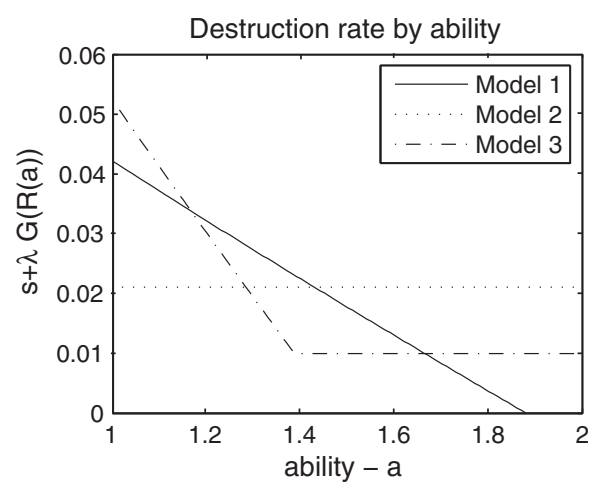

Fig. 5. Model properties (I): reservation productivity and job destruction rate by ability.

To compute wages densities, we then need to account for the endogenous job destruction decision as well. For instance, some highability workers may earn low wages at a certain point because their
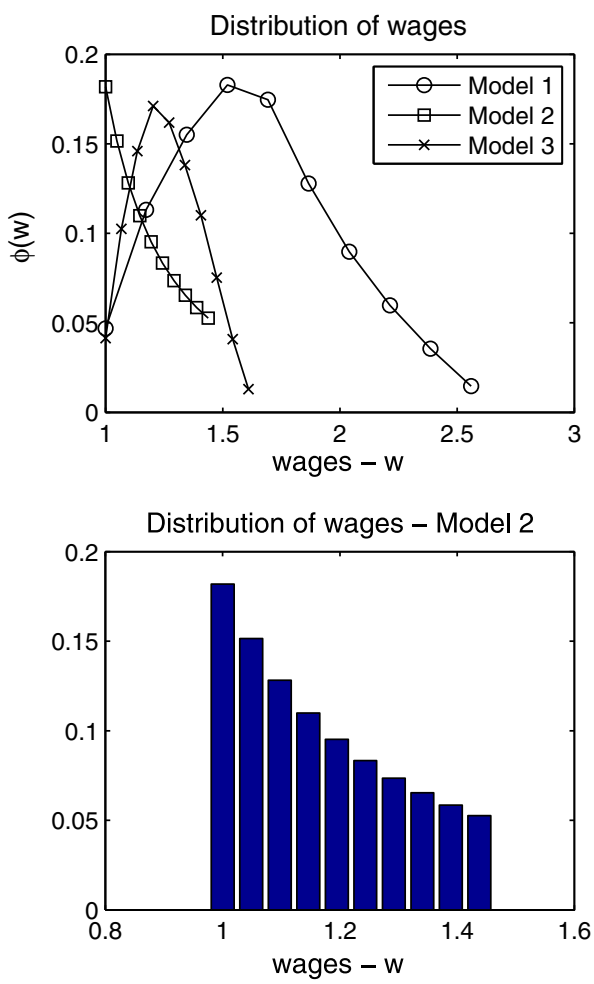

productivity threshold is low. Beyond this intuitive statement, the density of wages can be derived as follows:

$\varphi(w)=\int_{1}^{2} \Psi(w, a) d a \quad$ with $\left\{\begin{array}{l}\Psi(w, a)=0 \forall w<w(a, R(a)) \\ \Psi(w, a)=f(a)-u(a) \forall w \geq w(a, R(a))\end{array}\right.$

where we make use of the fact that the uniform distribution of shocks implies that the density of each productivity draw is unchanged all across the support of shocks.

\subsection{Numerical experiments}

This quantitative analysis first aims at showing how the shape of the wage distribution depends on endogenous reservation productivity. We then examine whether our model is able to produce realistic properties concerning both wage deciles and separation rates by wage interval.

Figs. 5 and 6 show the properties of the model. Fig. 7 compares some statistics calculated from the simulated data of the model with
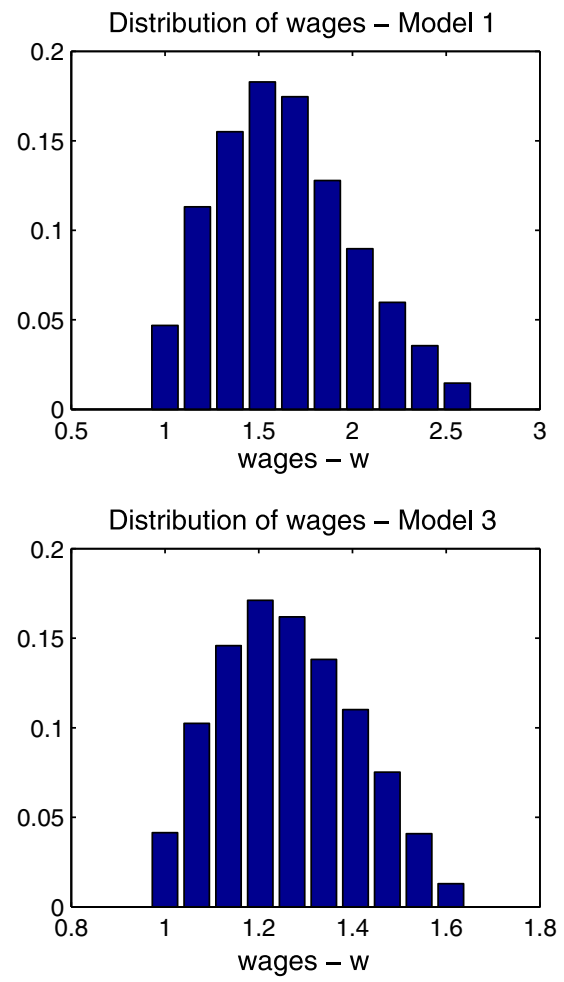

Fig. 6. Model properties (II): the distribution of wages.
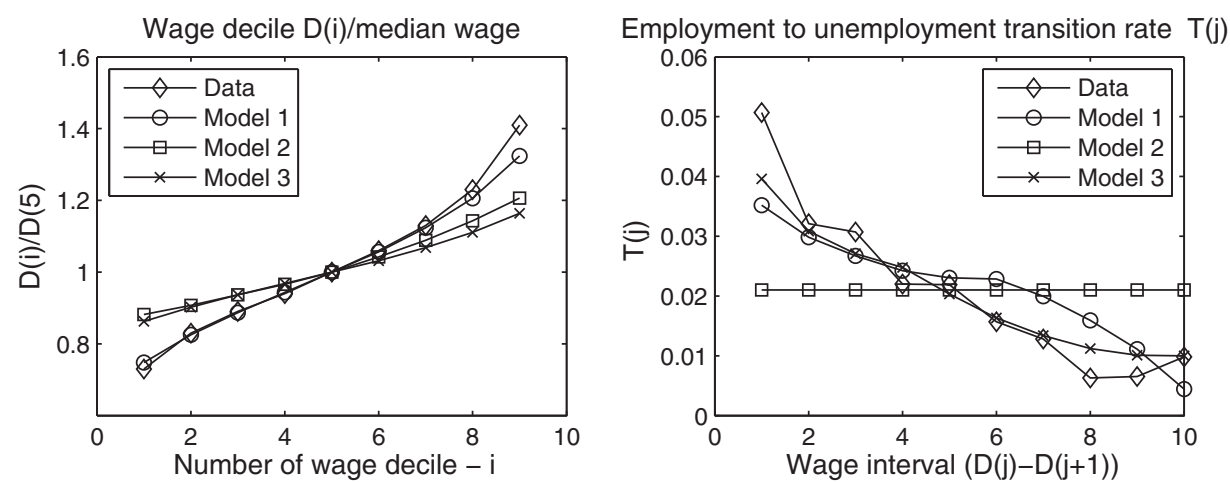

Fig. 7. Model assessment. 
the same statistics based on empirical data for the French low-skilled workers segment.

Fig. 5 cuses on job destruction rates. Benchmark Model 1 implies a decreasing relationship between the job destruction rate and worker ability: it starts with a quarterly rate of approximately $4 \%$ (per quarter) and falls to zero for workers whose ability is 1.9 times higher than the lowest one. Given the equilibrium distribution of abilities, around $5 \%$ of workers do not experience any employment to unemployment transitions. In Model 3, the lower bound of idiosyncratic shock is 0 instead of -1 in Model 1 . Workers whose abilities are above 1.4 then no longer experience endogenous firing, but face the exogenous employment exit rate of $1 \%$. This is due to the fact that their reservation productivity is limited by the lower bound 0 . Lastly, the endogenous job destruction rate in Model 2 clearly does not depend at all on abilities.

As a combination of the exogenous distributions of abilities and productivity shocks, the wage distribution is determined by firms' decision rule about reservation productivity. In Fig. $6,{ }^{16}$ the most striking feature is that introducing idiosyncratic productivity shocks generate hump-shaped wage distributions (Models 1 and 3). This first relies on the fact that the reservation productivity of low-ability workers is high, which implies that only low-ability workers who draw a good productivity are in a position to keep their job. All else being equal and compared with the case of exogenous separations, this raises the average wage of low-ability workers. Secondly, the reservation productivity of high-ability workers is low. Again, all else being equal, high-ability workers who have been hit by a bad productivity shock earn lower wages, which move them to the left in the wage distribution.

The magnitude of these mechanisms is all the more important when the gap between the lower bound of productivity shocks and the upper bound is large. This means that the potential role of firms' decisions is larger in Model 1. In Model 3, this gap is 1 (since $\underline{\varepsilon}=0$ ) while it is 2 in Model 1 (since $\underline{\varepsilon}=-1$ ). ${ }^{17}$ Thus, reservation productivities for high abilities workers turn out to be smaller in Model 1 than the lower bound of productivity shocks in Model 3. This implies that the shift to the left of high ability workers in the wage distribution is much stronger in Model 1 than in Model 3.

Finally, we compare the models' implications to some statistics computed from the group of low-skilled (manual skilled) workers in France. Fig. 7 reports two kinds of statistics. The panel on the left gives the value of each wage decile with respect to the median wage and the panel on the right gives the average job destruction rate according to the wage interval workers belong to. While other factors such as onthe-job search should improve our understanding of wage distributions, Model 1 performs surprisingly well. Ratios of wage deciles over the median wage are well-replicated, in particular deciles 1 to 4 . In the panel on the right, Model 2, by definition, cannot account for the decreasing shape of employment exit rates by wage interval. Both Models 1 and 3 match the data relatively well and generate similar patterns. Therefore, there is no basic difference between Models 1 and 3 in terms of worker flows by wage interval. But Model 1 clearly does a better job in replicating ratios of wages deciles than Model 3 thanks to the difference between both models in the lower bound of productivity shocks. As the latter is smaller in Model 1 (compared to Model 3), the mix of abilities actually rises within the wage distribution. This implies for instance that some-high ability workers could have much smaller wages in Model 1 than in Model 3, since their reservation productivity thresholds turn out to be lower than zero (the lower bound of shocks in Model 3).

Overall, although the performance of the model is not perfect, we think that these numerical experiments highlight the potential role of

\footnotetext{
${ }^{16}$ For each model calibration, we divide wages by the lowest wage.

17 Keep in mind that we assume an upper bound equal to 1 .
}

firms' decisions about reservation productivity in wage dispersion analysis.

\section{Conclusion}

The goal of this paper is to highlight the role of firms' decisions about reservation productivity (hence determining whether a job may be closed down) in the wage dispersion analysis. This has been neglected until now since existing models put the emphasis on onthe-job-search, and are usually characterized by exogenous firings. We have developed a matching model with endogenous job destructions (which implies endogenous reservation productivity) in combination with heterogeneous workers. By letting the range of productivity shocks vary from zero, we showed that the model can generate a hump-shaped wage distribution.

We do not want to disregard or diminish the role the contribution of on-the-job search in analyzing wage dispersion analysis. Rather, on-thejob search and endogenous firing decisions should be considered together in order to provide a good description of wage inequality. This gives a research agenda, as well as providing a decomposition of cross-employee wage variance in line with Postel-Vinay and Robin (2002) and Cahuc et al. (2006) who use matched employer-employee data.

\section{References}

Albrecht, J., Vroman, S., 2002. A matching model with endogenous skill requirements. International Economic Review 43 (1), 283-305.

Andolfatto, D., 1996. Business cycles and labor market search. American Economic Review 86 (1), 112-132.

Blàquez, M., Jansen, M., 2008. Search, mismatch and unemployment. European Economic Review 52 (3), 498-526.

Bontemps, C., Robin, J.M., van den Berg, G., 1999. An empirical equilibrium job search model with search on the job and heterogeneous workers and firms. International Economic Review 40 (4), 1039-1074.

Bontemps, C., Robin, J.M., van den Berg, G., 2000. Equilibrium search with continuous productivity dispersion: theory and nonparametric estimation. International Economic Review 41 (2), 305-358.

Burdett, K., Mortensen, D., 1998. Wage differentials, employer size, and unemployment International Economic Review 2 (39), 257-273.

Cahuc, P., Postel-Vinay, F., Robin, J.M., 2006. Wage bargaining with on-the-job search: theory and evidence. Econometrica 74 (2), 323-364.

Chéron, A., Langot, F., 2004. Labor market search and real business cycles: reconciling Nashbargaining with real aage dynamics. Review of Economic Dynamics 7 (2), 476-493.

Chéron, A., Hairault, J.-O., Langot, F., 2011. Age-dependent employment protection. Forthcoming in Economic Journal.

Cole, H., Rogerson, R., 1999. Can the Mortensen-Pissarides matching model match the Business Cycle facts. International Economic Review 40 (4), 933-959.

Dolado, J., Jansen, M., Jimeno, J., 2009. On-the-job search in a matching model with heterogeneous jobs and workers. Economic Journal 119 (534), 200-228.

Hall, R.E., 2005. Employment fluctuations with equilibrium wage stickiness. American Economic Review 95 (1), 50-65.

Hall, R.E., Milgrom, P., 2008. The limited influence of unemployment on the wage bargain. American Economic Review 98 (4), 1653-1674.

Jolivet, G., Postel-Vinay, F., Robin, J.-M., 2006. The empirical content of the job search model: labor mobility and wage distributions in Europe and the US. European Economic Review 50 (4), 877-907.

Ljungqvist, L., Sargent, T., 2008. Two questions about European unemployment. Econometrica 76 (1), 1-29.

Merz, M., 1995. Search in the labor market and the Real Business cycle. Journal of Monetary Economics 36 (2), 269-300.

Millard, S., 1996. The cyclial effects of labour market policy. In: Hénin, P.Y. (Ed.), Advanced Business Cycle Theory. Springler Verlaag.

Mortensen, D., 2003. Wage Dispersion: Why are Similar People Paid Differently. The MIT Press.

Mortensen, D., Pissarides, C., 1994. Job creation and job destruction in the theory of unemployment. Review of Economic Studies 61 (3), 397-415.

Mortensen, D., Pissarides, C., 1999. New developments in models of search in the labor market, In: Ashenfelter, O., Card, D. (Eds.), 1st ed. Handbook of Labor Economics, Vol. 3. Elsevier, pp. 2567-2627. Chapter 39.

Pissarides, C., 2000. 2nd ed. Equilibrium Unemployment Theory, Vol. 1. The MIT Press

Pissarides, C., 2009. The unemployment volatility puzzle: is wage stickiness the answer? Econometrica 77 (5), 1339-1369.

Postel-Vinay, F., Robin, J.M., 2002. Equilibrium wage dispersion with worker and employer heterogeneity. Econometrica 70 (6), 2295-2350.

Shimer, R., 2005. The cyclial behavior of equilibrium unemployment and vacancies. The American economic Review 95 (1), 25-49.

Shimer, R., Smith, L., 2001. Matching, search, and heterogeneity. The B.E. Journal of Macroeconomics 0 (1). 